\title{
Role of proneural genes in the formation of the larval olfactory organ of Drosophila
}

\author{
Nicola Grillenzoni • Véronique de Vaux • \\ Jocelyne Meuwly • Séverine Vuichard • \\ Andrew Jarman • Eimear Holohan • Nanaë Gendre • \\ Reinhard F. Stocker
}

Received: 25 October 2006 / Accepted: 9 January 2007 / Published online: 27 January 2007

(C) Springer-Verlag 2007

\begin{abstract}
In this paper, we address the role of proneural genes in the formation of the dorsal organ in the Drosophila larva. This organ is an intricate compound comprising the multineuronal dome - the exclusive larval olfactory organand a number of mostly gustatory sensilla. We first determine the numbers of neurons and of the different types of accessory cells in the dorsal organ. From these data, we conclude that the dorsal organ derives from 14 sensory organ precursor cells. Seven of them appear to give rise to the dome, which therefore may be composed of seven fused sensilla, whereas the other precursors produce the remaining sensilla of the dorsal organ. By a loss-of-function approach, we then analyze the role of atonal, amos, and the achaetescute complex $(A S-C)$, which in the adult are the exclusive proneural genes required for chemosensory organ specification. We show that atonal and amos are necessary and sufficient in a complementary way for four and three of the sensory organ precursors of the dome, respectively. $A S-C$, on the other hand, is implicated in specifying the non-olfactory sensilla, partially in cooperation with atonal and/or amos. Similar links for these proneural genes with olfactory and gustatory function have been established in the adult fly.
\end{abstract}

Communicated by P. Simpson

N. Grillenzoni and V. de Vaux contributed equally to this work.

N. Grillenzoni $\cdot$ V. de Vaux $\cdot$ J. Meuwly $\cdot$ S. Vuichard

N. Gendre $\cdot$ R. F. Stocker $(\square)$

Department of Biology, University of Fribourg,

Chemin du Musée 10,

1700 Fribourg, Switzerland

e-mail: reinhard.stocker@unifr.ch

A. Jarman · E. Holohan

Centres for Integrative Physiology and Neuroscience Research,

School of Biomedical Sciences, University of Edinburgh,

Edinburgh EH8 9XD, UK
However, such conserved gene function is not trivial, given that adult and larval chemosensory organs are anatomically very different and that the development of adult olfactory sensilla involves cell recruitment, which is unlikely to play a role in dome formation.

Keywords Proneural genes · Dorsal organ .

Olfactory receptor neurons $\cdot$ Embryogenesis $\cdot$ Drosophila

\section{Introduction}

During the development of the insect peripheral nervous system, proneural genes render groups of ectodermal cells neurally competent (Jan and Jan 1994; Cabrera 1992; Ghysen et al. 1993). From such a 'neurogenic' group of cells, a single sensory organ precursor cell (SOP) is then selected via Delta-Notch-mediated lateral inhibition (Simpson 1990). Subsequently, proneural gene expression becomes restricted to the SOP, and these genes now accomplish a second role in specifying sensory organ identity (Jarman et al. 1993, 1994; Huang et al. 2000). Via a genetically fixed cell-lineage, the SOP then gives rise to a differentiated sensillum comprising a socket (tormogen) cell, a shaft (trichogen) cell, a sheath (thecogen) cell, and a variable number of sensory neurons, depending on the type of sensillum (Hartenstein and Posakony 1989; Fichelson and Gho 2003; Lai and Orgogozo 2004). However, for adult olfactory sensilla, such strict lineage does not apply. Rather, a founder cell appears to recruit neighboring cells, which are not related to the founder cell by lineage (Ray and Rodrigues 1995; Reddy et al. 1997).

In Drosophila, the essential members of the proneural gene family (Bertrand et al. 2002) include the achaete-scute complex ( $A S-C$; Villares and Cabrera 1987; Romani et al. 1989), atonal (ato; Jarman et al. 1993), and amos 
(Goulding et al. 2000; Huang et al. 2000). In the adult chemosensory system, $A S-C$ is required for the specification of taste bristles (Ray and Rodrigues 1994) but not of olfactory sensilla. The only proneural genes implicated in adult olfactory sensilla formation appear to be ato and amos. The former is involved in specifying all olfactory sensilla on the maxillary palp and of coeloconic antennal sensilla (Gupta and Rodrigues 1997; Jhaveri et al. 2000), whereas amos controls basiconic and trichoid sensilla formation on the antenna (Goulding et al. 2000; zur Lage et al. 2003).

Are $A S-C$, ato, and amos also involved in the development of the much simpler although anatomically very distinct larval chemosensory organs? In the adult fly, one to four olfactory receptor neurons (ORNs), from a total of about 1,300 , are included in about 500 individual sensilla (Stocker 2001). Similarly, adult gustatory receptor neurons are collected in numerous taste sensilla. The larva, in contrast, comprises only a small fraction of the numbers of adult olfactory and gustatory neurons, and the larval neurons are collected in very few chemosensory organs. The two dominant among them are the dorsal organ (DO) and the terminal organ on the cephalic hemispheres (Singh and Singh 1984; Python and Stocker 2002; Gendre et al. 2004). Whereas the terminal organ serves essentially gustatory function, the DO is a mixed smell and taste organ. It is composed of the central olfactory 'dome' and six peripheral, mostly gustatory sensilla. The multiporous dome is innervated by seven triplets of dendrites originating from 21 ORNs, which are in fact the sole larval ORNs (Larsson et al. 2004; Fishilevich et al. 2005). Each of them expresses the atypical odorant receptor OR83b and one or two conventional odorant receptors (Fishilevich et al. 2005; Kreher et al. 2005). Apart from the 21 ORNs, the ganglion of the DO includes another 15 sensory neurons (Python and Stocker 2002). Twelve of these innervate the six peripheral DO sensilla, whereas the three remaining neurons extend atypically to the neighboring terminal organ (Kankel et al. 1980; Python and Stocker 2002). The exact cellular composition of the different DO sensilla is not known.

Hence, the larval chemosensory equipment is very simple in terms of cell numbers. However, considering its mixed modality and multisensillar composition, the DO seems much more complex than the adult sensilla. The involvement of the three known adult proneural genes in DO formation is therefore not predictable. Interestingly, complex larval chemosensory organs are known from other species; an example is the plate organ of tenebrionid larvae, which includes about 130 sensory neurons (Behan and Ryan 1978).

In this study, by counting accessory cells in the DO, we first determine the likely numbers of SOPs that give rise to the DO and to its different sensilla. By a loss-of-function approach, we then analyze the contribution of ato, amos, and $A S-C$ in the specification of the DO neurons in general and of the 21 ORNs in particular. We show that ato and amos are necessary and sufficient in a complementary way for four and three of the olfactory SOPs, respectively. $A S-C$, on the other hand, is implicated in specifying the non-olfactory sensilla, partially in cooperation with ato and/or amos.

\section{Materials and methods}

\section{Drosophila stocks}

The following strains were studied: wild-type Canton $\mathrm{S}$ (CS), amos ${ }^{1} / D f S 6$, amos $^{1} / C y O e n^{11} l a c Z$ (zur Lage et al. 2003), amos-3.5-GFP (Holohan et al. 2006), ato ${ }^{I} / T M 3$ Sb lacZ (Jarman et al. 1993), ato-Gal4 (Hassan et al. 2000), $s c^{19} / F M 6 c, s c^{B 57} / F M 6 c$ (both from Bloomington Stock Center), Y114 (w; D-Pax2-lacZ; generously provided by Werner Boll, Zürich), and 4551-Gal4 (from J.F. Ferveur, Dijon). Stocks were raised on standard cornmeal-yeastagar medium at $25^{\circ} \mathrm{C}$.

\section{Immunohistochemistry}

Standard embryo fixing and staining protocols (Patel 1994) were used throughout. As primary antibodies, we applied rabbit anti-green-fluorescent-protein (GFP) $(1: 1,000$; Molecular Probes), mouse 22C10 (1:100; Iowa Hybridoma Bank), rat anti-SuH (1:500; preabsorbed), rabbit anti-betagalactosidase $(1: 1,000$; preabsorbed; Cappel), mouse antiProspero (1:4), rat anti-Elav (1:100; both from Iowa H. B.), rabbit anti-Amos (1:5,000; zur Lage et al. 2003), sheep anti-Ato (1:5,000; Holohan et al. 2006). The following secondary antibodies were used: goat anti-rabbit Alexa 488 (Molecular Probes), goat anti-mouse Cy3 (Jackson Immuno), goat anti-mouse Alexa 568, 488, and 647 (Molecular Probes), goat anti horseradish peroxidase (HRP)-flourescein isothiocyanate (FITC) conj (1:50), goat anti-HRP-Cy5 conj (1:20), goat anti-guinea pig FITC (all three from Jackson), goat anti-rat Alexa 488, and goat antirat $\mathrm{Cy} 3$ (both from Molecular Probes). Except for the two goat anti-HRP-antibodies, the secondary antibodies were used at 1:200.

Nuclei were stained either by incubating specimens with propidium iodide $(5 \mu \mathrm{g} / \mathrm{ml})$ or with Draq5 (1:250; Biostatus). For non-fluorescent staining, diaminobenzidine labeling was performed using the Vectastain ${ }^{\circledR} \mathrm{ABC}$ kit. Embryos were mounted either in Vectashield (Vector) or in $80 \%$ glycerol, and the specimens were kept at $4^{\circ} \mathrm{C}$.

In situ hybridization

An RNA probe of Or83b (kindly provided by L.B. Vosshall, Rockefeller University, New York) labeled with 
digoxygenin (DIG) was used to localize ORNs (Vosshall et al. 1999). The RNA in situ procedure is based on the protocol developed by Tautz and Pfeifle (1989; see also Berkeley Drosophila Genome Project method in (http:// www.fruitfly.org/about/methods/RNAinsitu.html). DIG was detected with sheep anti-DIG coupled to peroxidase (Roche) and fluorescently labeled using the tyramide amplification system (Perkin-Elmer).

\section{Confocal and electron microscopy}

We used a BioRad MRC confocal microscope 1024 equipped with a $\mathrm{Kr} / \mathrm{Ar}$ laser. For image treatment, LaserSharp 2000 and ImageJ softwares (Abramoff et al. 2004) were applied. For electron microscopy, head parts of third instar larvae were dissected in phosphate-buffered saline (PBS) and fixed for $1 / 2 \mathrm{~h}$ on ice in $3 \%$ glutaraldehyde dissolved in PBS+Triton X-100 0.2\% (PBT). After washing in PBT, tissues anterior to the mouth hook were postfixed in $2 \% \mathrm{OsO} 4$ (in $\mathrm{PBT}$ ) for $2 \mathrm{~h}$ at $4^{\circ} \mathrm{C}$, washed in $\mathrm{PBT}$, dehydrated in a graded series of ethanol, transferred to propylenoxide and to a mixture of propylenoxide/epon, and embedded in epon. Ultrathin sections were counterstained with $2 \%$ uranyl acetate and lead citrate. Images were collected with a Philips CM100 Biotwin transmission electron microscope.

\section{Results}

Cellular composition of the dorsal organ

The DO of third instar larvae was previously shown to comprise 36-37 sensory neurons (Python and Stocker 2002), which is confirmed in this study for embryonic stage 16 (Fig. 1a,b). This suggests that the DO is formed before stage 16 and does not change its cellular composition during larval life. Likewise, by in situ hybridization with an RNA probe from the atypical odorant receptor gene Or $83 b$, we observed, on an average, 21 ORNs at embryonic stage 16, in agreement with observations in the third larval instar (Larsson et al. 2004; Fishilevich et al. 2005) (Fig. 1c). We then counted the accessory cells of the DO at stage 16 either immunocytochemically or by studying expression patterns of particular driver lines. By applying $\alpha$-Prospero, which at this stage labels specifically sheath cells (Doe et al. 1991; Vaessin et al. 1991), we counted, on an average, 14 of these cells (Fig. 1d). For shaft cell labeling, we used the driver line Y114 (W. Boll) that expresses lac $Z$ under the peripheral nervous system enhancer of D-Pax2, a transcriptional regulator of shaft cell differentiation. Because at stage 16, D-Pax2 gene expression includes both prospective shaft and sheath cells
(Kavaler et al. 1999), the latter were 'subtracted' by $\alpha$ Prospero labeling (see above). In this way, we identified, on an average, 14 shaft cells (Fig. 1e). Finally, by applying an antibody against $\mathrm{Su}(\mathrm{H})$, a protein that accumulates in the nuclei of future socket cells (Gho et al. 1996), we found, on an average, 13 of these cells (Fig. 1f). We noticed that the cell bodies of the neurons and the three types of accessory cells are located at distinct proximo-distal levels in the DO ganglion. Neurons occupy the most proximal level, followed by sheath cells, shaft cells, and socket cells, whose nuclei are located closest to the base of the dendrites (cf. Fig. 1c-f).

Role of proneural genes in dorsal organ formation

To investigate the role of ato, amos, and $A S-C$ in DO formation, we counted the neurons in the DO ganglion in loss-of-function mutants. A genetic null phenotype has been demonstrated for the alleles ato ${ }^{l}$ (Jarman et al. 1994, 1995) and $\operatorname{amos}^{1}$ (Goulding et al. 2000; Huang et al. 2000; zur Lage et al. 2003). The $s c^{19}$ allele (Campuzano and Modolell 1992) deletes the three proneural gene constituents of $A S-C$, i.e., achaete, scute, and lethal of scute, but leaves the asense gene intact (Garcia-Bellido 1979), which is not involved in SOP selection (Bertrand et al. 2002). A second deficiency, $s c^{B 57}$, affects the entire complex including asense (González et al. 1989).

In each of the three mutants, ato ${ }^{1}$, amos ${ }^{1}$, and $s c^{19}$, neurons in the DO ganglion were reduced by number, most severely in ato $^{l}$ (Fig. 2a), demonstrating that ato, amos, and $A S-C$ are all involved in DO formation. The sum of the lost neurons in the three mutants was 28 on an average, which is smaller than the total of 36 neurons in the CS control. This suggests either functional redundancy between ato, amos, and $A S-C$ or the implication of (an) additional proneural gene(s). To investigate this issue, we compared the numbers of missing neurons in mutant pairs with the number of missing neurons in double mutants (Fig. 2b). For $s c^{19}$ amos $^{1}$ or ato $^{1}$-amos ${ }^{1}$ combinations, neuron numbers in the two situations did not differ significantly, implying that amos acts independently of the other proneural genes. In contrast, the $s c^{19}$; ato ${ }^{1}$ double mutant had lost 22 neurons, whereas $s c^{19}$ and ato ${ }^{1}$ single mutants together were lacking only 19 neurons. This suggests a functional interaction between $A S-C$ and ato in the formation of some neurons of the DO. Rare triple mutants $s c^{B 57}$; amos $^{1}$; ato ${ }^{1}$ had lost all the neurons of the DO (Fig. 2b). Unfortunately, at embryonic stage 16, $s c^{19}$; amos $^{1}$; ato ${ }^{1}$ escapers were not recovered. However, we were unable to detect any significant differences in DO neuron numbers between $s c^{19}$ and $s c^{B 57}$ mutant embryos (data not shown).

If amos acts independently of ato and $A S-C$, it may be expected that its expression pattern does not overlap with 

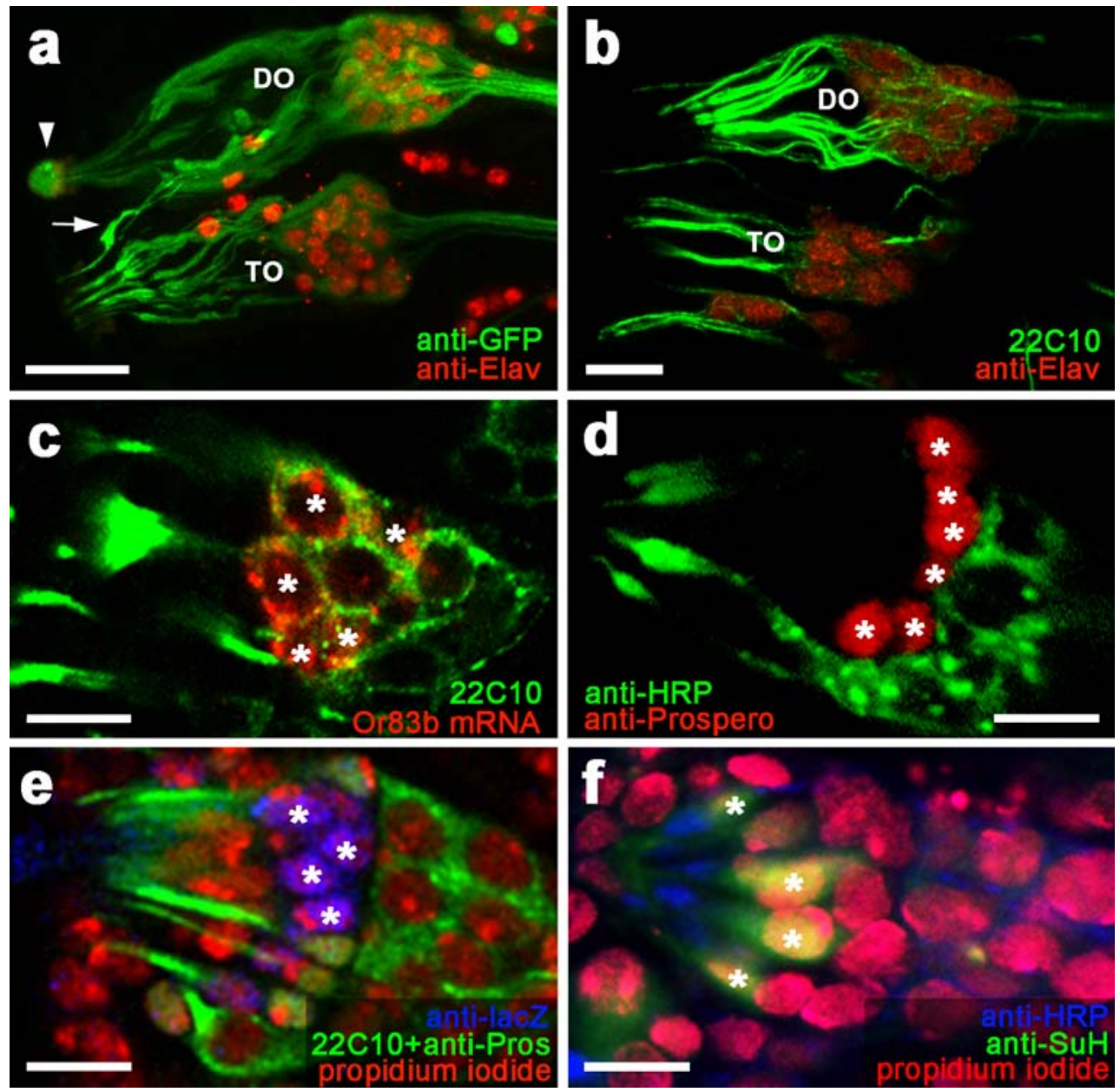

Fig. 1 Cellular composition of the dorsal organ $(D O)$ in the third larval instar (a) and at embryonic stage 16 (b-f) in the wild type CS (except a and e). a The 4551-Gal4 driver line (green) labels both DO and terminal organ (TO; Python and Stocker 2002). The ganglion of the DO contains 36-37 sensory neurons ( $\alpha$-Elav staining); the 21 ORNs among them extend their dendrites into the dome (arrowhead), 3 other DO neurons project into a sensillum of the TO (arrow) and the remaining 12 neurons innervate six sensilla at the base of the dome (not shown by the 4551 pattern). b In late embryos, the DO is composed of 36 neurons on average ( $n=13$; nuclei stained by $\alpha$-Elav, cytoplasm by $22 \mathrm{C} 10)$. c In situ hybridization with ORN-specific Or $83 b$ mRNA reveals the presence of 21 ORNs (examples marked by

asterisks) among the 36 neurons ( $n=16$; cytoplasm stained by $22 \mathrm{C} 10$ ). d $\alpha$-Prospero staining allows to count a total of 14 sheath cells (examples marked by asterisks; $n=26$ ). Neuronal cytoplasm stained by $\alpha$-HRP. e The Y114-lacZ driver (blue) shows specific expression in shaft and sheath cells. After 'subtracting' the sheath cells by $\alpha$ Prospero staining (green), 14 shaft cells remain (examples marked by asterisks; $n=10)$. Additional green staining (22C10) labels neuronal cytoplasm. Nuclei are labeled by propidium iodide (red). f Staining with $\alpha$-Suppressor-of-Hairless (green) reveals a total of 13 socket cells (examples marked by asterisks; $n=13$ ). Neuronal cytoplasm labeled by $\alpha$-HRP (blue) and nuclei by propidium iodide (red). In all panels, anterior is to the left. Scale bars: $20 \mu \mathrm{m}(\mathbf{a}), 10 \mu \mathrm{m}(\mathbf{b}-\mathbf{f})$

those of ato and $A S-C$. Embryos were examined for the expression of $s c$, which is the major $A S-C$ proneural gene involved in sensory nervous system development. Costaining with antibodies against Amos and Sc confirms that there is no obvious expression overlap in the DO region for these proteins (data not shown). However, costaining for Ato and Amos revealed a more complex picture. These proteins are not only expressed mutually exclusively in two clusters of cells, but are also coexpressed in a third adjacent cluster (Fig. 3a). To clarify this, we examined the pattern of Amos expression in ato ${ }^{l}$ embryos and vice versa (Fig. 3b,c). Notice that in both ato $^{l}$, which is a missense point mutation (Jarman et al. 1994), and $\operatorname{amos}^{l}$, which is a nonsense point mutation (zur Lage et al. 2003), the mutant proteins are still detectable. As expected, the mutually exclusive expression of each proneural gene did not depend on the function of the other gene. However, for the cluster that shows overlapping expression, Amos expression did not depend on ato function, but the expression of Ato was lost in amos ${ }^{l}$ embryos (Fig. 3b,c). This suggests that amos provides the proneural function in the region of coexpression, whereas ato is expressed in response to the amos proneural function.

Interestingly, simultaneous amos-GFP (Holohan et al. 2006) and ato-Gal4/UAS-lacZ reporter expression showed 
Fig. 2 Effect of proneural mutants on neuron numbers in the embryonic DO ganglion (stage 16). a Comparing the neuron numbers in the wild type CS $(n=13)$ with the loss-offunction alleles $s c^{19}(n=18)$, $\operatorname{ato}^{I}(n=9)$, and $\operatorname{amos}^{l}(n=17)$ shows that $A S-C$, ato, and amos all affect neuronal specification. b Missing neurons in the DO ganglion in different mutant situations. The single mutant data in columns $1-3$ correspond to those in (a). In the column pairs $4 / 5,6 / 7$, and $8 / 9$, the effects of double mutants are compared with the added effects of the corresponding single mutants. In the $s c^{19}$; ato ${ }^{I}$ double mutant $(n=14)$, three more neurons are missing than in the $s c^{19}$ and $a t o^{1}$ single mutants, whereas for the $s c^{19}$; amos $^{1}$ double mutant $(n=15)$ and the amos $^{l} ;$ ato $^{l}$ double mutant $(n=15)$, neuron numbers are the same as in the corresponding single mutants. Columns 10/11 refer to rare cases of triple mutants (involving the $s c^{B 57}$ allele) and to the combination of $s c^{19}, \operatorname{amos}^{1}$, and ato $^{l}$, respectively. $n$ Numbers of cases analyzed ( $n$ 's are not indicated for the columns referring to the added effects of single mutants). Error bars SEM

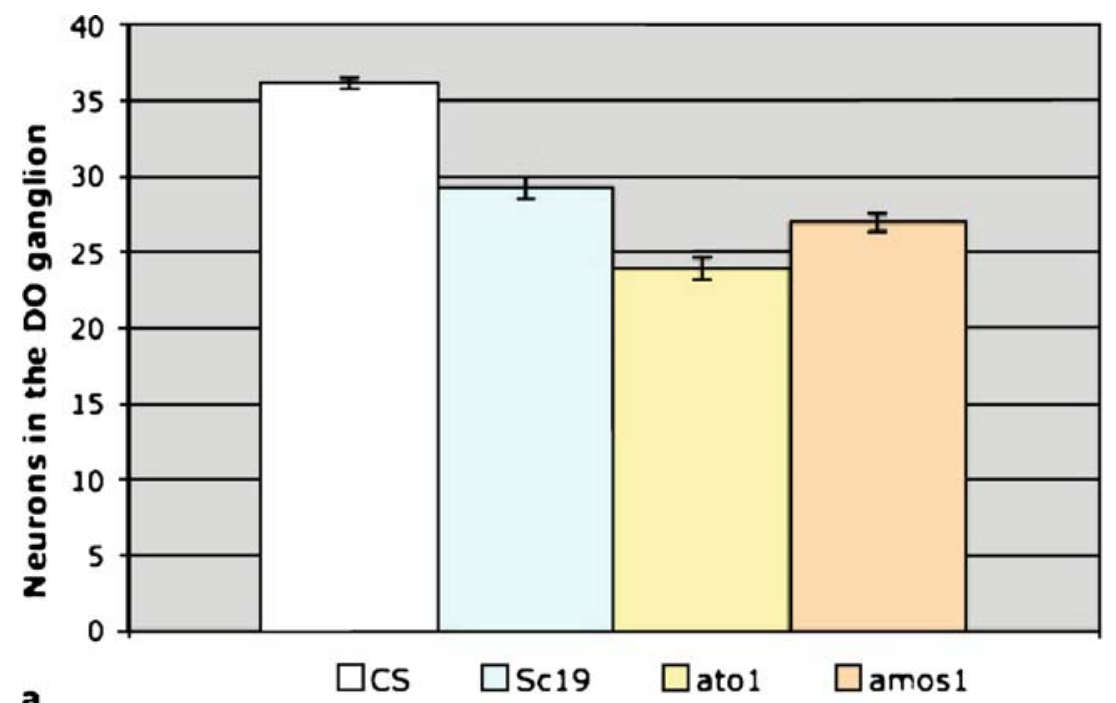

a

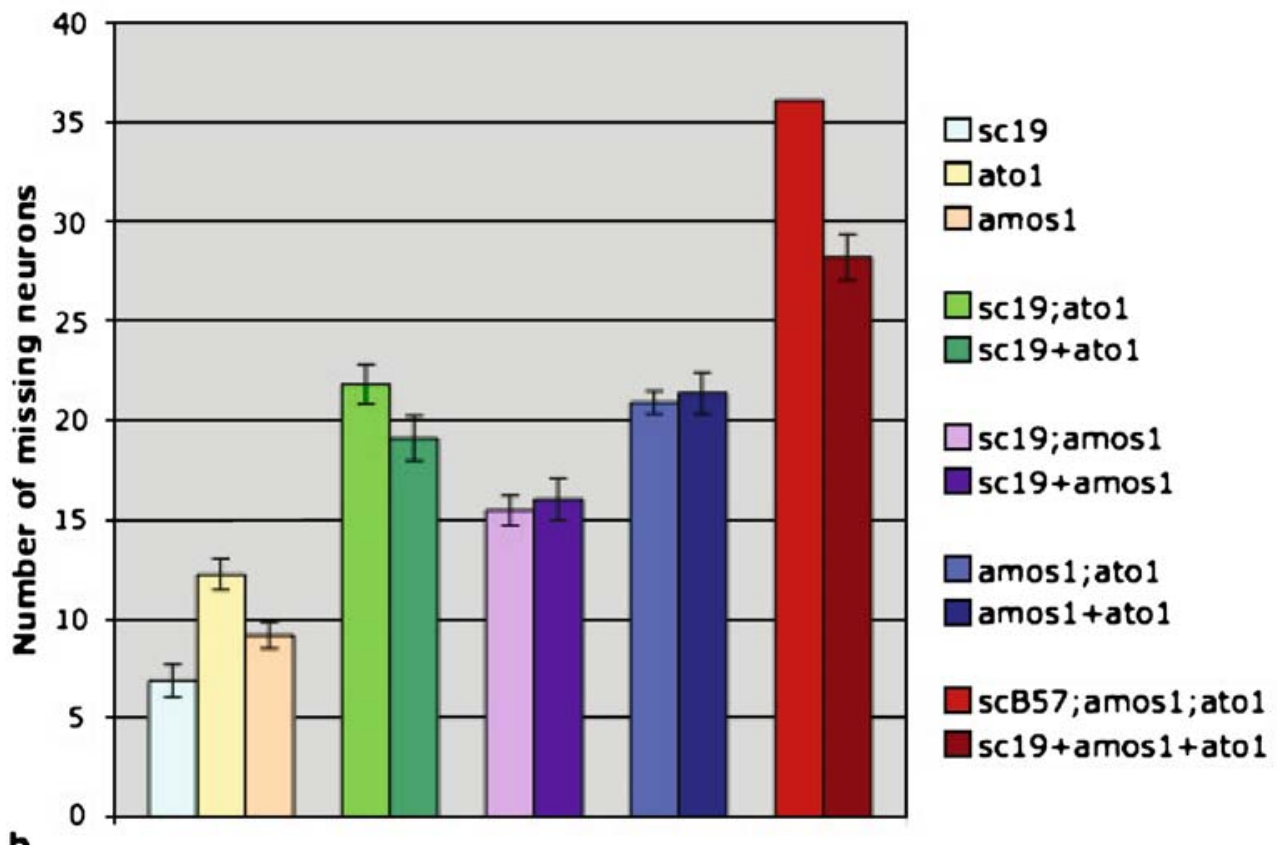

mutually exclusive labeling in the future DO, without expression of the ato reporter in the region of overlapping expression (cf. Fig. 3d-f). This suggests that the nonproneural (amos-dependent) element of ato expression in the DO is under the control of a different enhancer, which is not present in the ato-Gal4 driver construct. Note that the same ato-Gal4 line also does not report ato expression in trunk dbd neuron formation in which ato is also downstream of amos proneural function (Holohan et al. 2006). The complementary pattern of GFP and LacZ in the prospective DO region persisted from embryonic stage 12 to 16 , although the two sets of cells changed their relative positions (Fig. 3e-g). Although the ato-driven cells initially occupied a dorsoposterior site, they later on moved to an anteroventral position; the reverse situation applied to the amos-driven cells. Taken together, expression pattern analysis is in agreement with the proposed independence of amos from ato, and amos from $A S-C$.

Role of proneural genes in the formation of olfactory receptor neurons

By in situ hybridization with RNA from $0 r 83 b$, we then counted the numbers of ORNs in the three mutants (Figs. 4 and 5). Interestingly, the entire set of 21 ORNs persisted in $s c^{19}$ (Fig. 4a). In contrast, we observed, on an average, only 8 ORNs in ato $^{1}$ (Fig. 4b) and 12 ORNs in amos $^{1}$ (Fig. 4c), as well as a total elimination of ORNs in the double mutant amos $^{1}$; ato $^{1}$ (Fig. 4d). The loss of ORNs in ato ${ }^{1}$ and amos ${ }^{1}$ was further investigated by studying the dendritic arrange- 

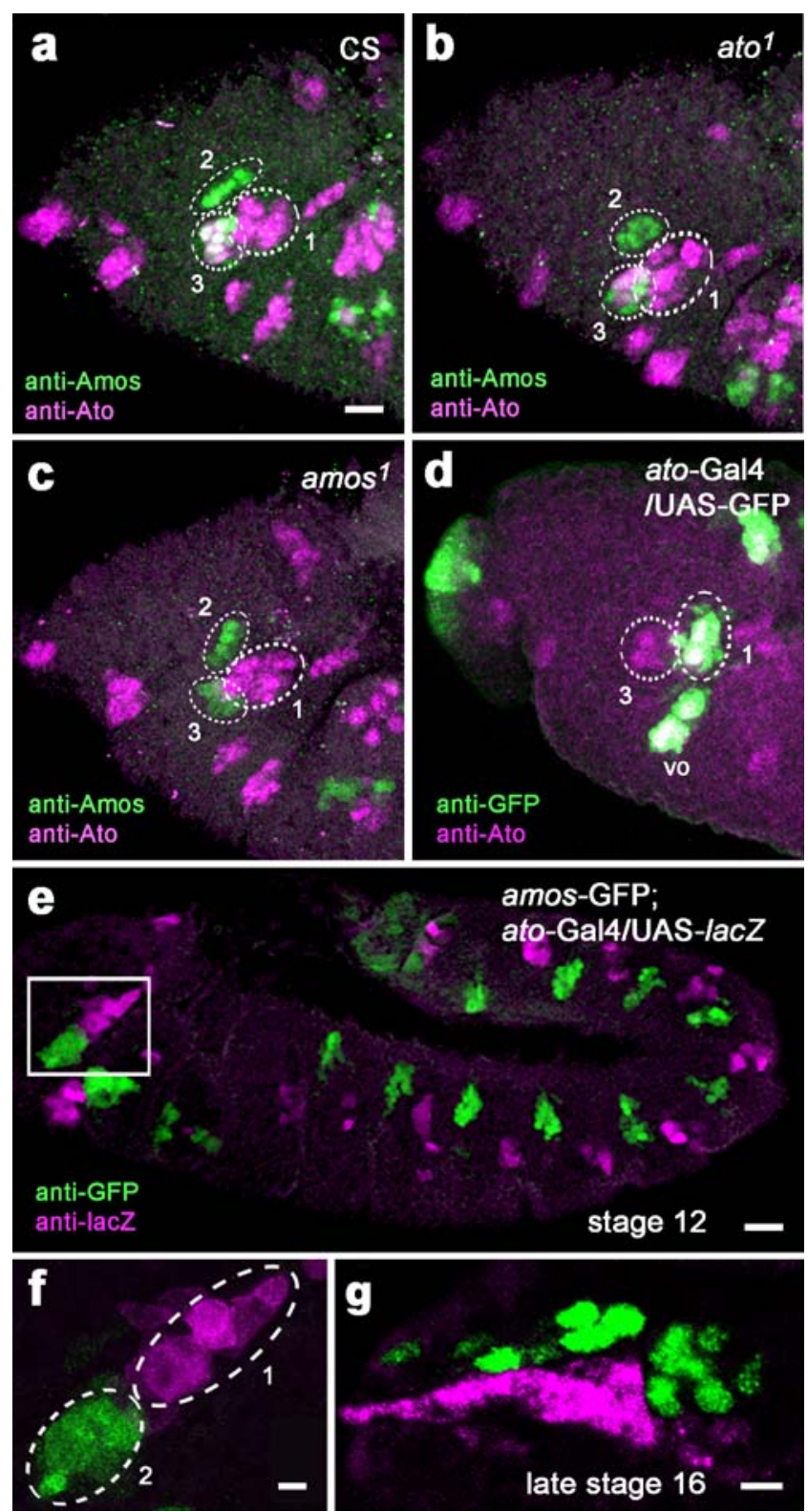

Fig. 3 Expression patterns of ato and amos in the embryonic DO (a-d, stage 11). a Costaining with the antibodies indicated shows that in the DO anlage of the wild type, Ato and Amos are expressed mutually exclusively in cell clusters 1 and 2 , respectively, and are coexpressed in cluster 3. (b, c) In both ato ${ }^{l}$ and $\operatorname{amos}^{l}$, the mutually exclusive expression of each proneural gene in clusters 1 and 2 does not depend on the function of the other gene. For cluster 3, Amos expression does not depend on ato function, but the expression of Ato is lost in amos ${ }^{I}$ embryos. Note that in both ato ${ }^{l}$ and $\operatorname{amos}^{l}$, the mutant proteins are still detectable. $\mathbf{d}$ In the ato-Gal4 driver, cluster 3 expresses Ato but is not labeled by the driver line (vo ventral organ). e, f, $\mathbf{g}$ Simultaneous amos-GFP and ato-Gal4/UAS-lacZ reporter expression also shows mutually exclusive labeling in clusters 1 and 2 but no expression of the ato reporter in the region of overlapping expression ( $\mathbf{f}$ is a close-up of the region boxed in $\mathbf{e}$ ). The complementary patterns persist from stage $12(\mathbf{e}, \mathbf{f})$ to stage $16(\mathrm{~g})$ and beyond, but the two cell clusters change their relative positions. In all panels, anterior is to the left. Scale bars: $20 \mu \mathrm{m}$ [a (for a-d), e], $5 \mu \mathrm{m}$ (f, $\mathbf{g}$ ) ment of ORNs inside the dome at the fine structural level (Fig. 6a). Consistent with cell counting, ato ${ }^{1}$ and amos $^{1}$ mutants both reduced the numbers of ORN dendrites. In $\operatorname{amos}^{1}$, we observed four triplets of dendrites (Fig. 6b), whereas in ato $^{1}$ eight dendrites were found to be grouped as two triplets and a pair (Fig. 6c). Moreover, ato ${ }^{1}$ displayed some variability in dendritic fine structure (Fig. 6d). The

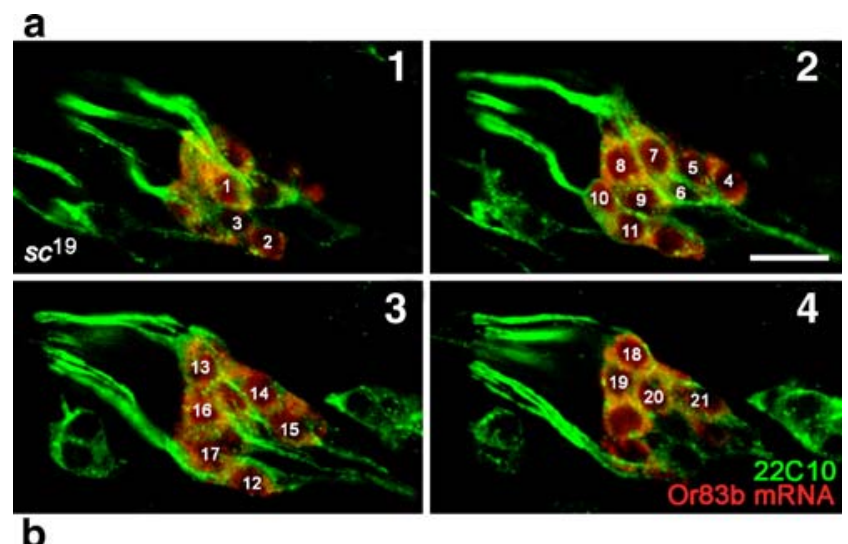

b

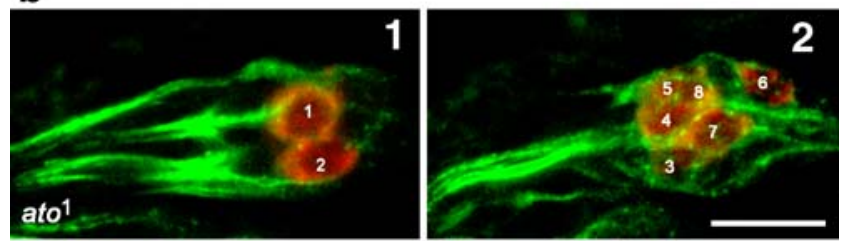

C
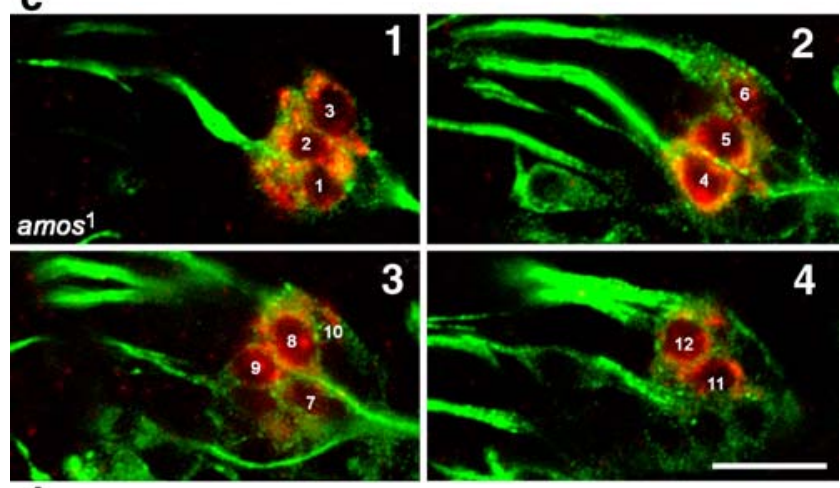

d

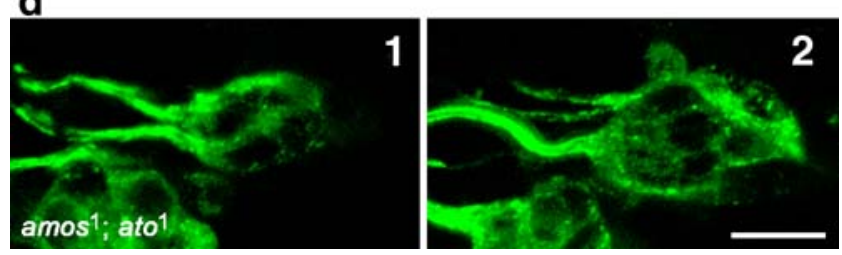

Fig. 4 Effects of proneural mutants on ORN numbers in the embryonic DO (stage 16) shown by in situ hybridization with $\mathrm{Or} 83 \mathrm{~b}$ mRNA (red). Whereas in $s c^{19}$ the full complement of 21 ORNs remains (a, 1-4), only 8 ORNs were counted in ato ${ }^{1}(\mathbf{b}, 1$ and 2$)$ and 12 ORNs in $\operatorname{amos}^{l}$ (c, 1-4). In the $\operatorname{amos}^{l} ;$ ato ${ }^{l}$ double mutant, all ORNs have disappeared (d, 1 and 2). The neuronal cytoplasm is labeled by $22 \mathrm{C} 10$ (green). In all panels, anterior is to the left. Scale bars: $10 \mu \mathrm{m}$ 
Fig. 5 Numbers of ORNs in the embryonic DO ganglion of the wild type (column 1), the single mutants (columns 2-4), the amos $^{1}$; ato ${ }^{1}$ double mutant (column 5) and the sum of amos $^{l}$ and ato $^{l}$ mutants (column 6). $n$ Number of cases analyzed (not indicated for the last column referring to the added effects of the two mutants). Error bars SEM

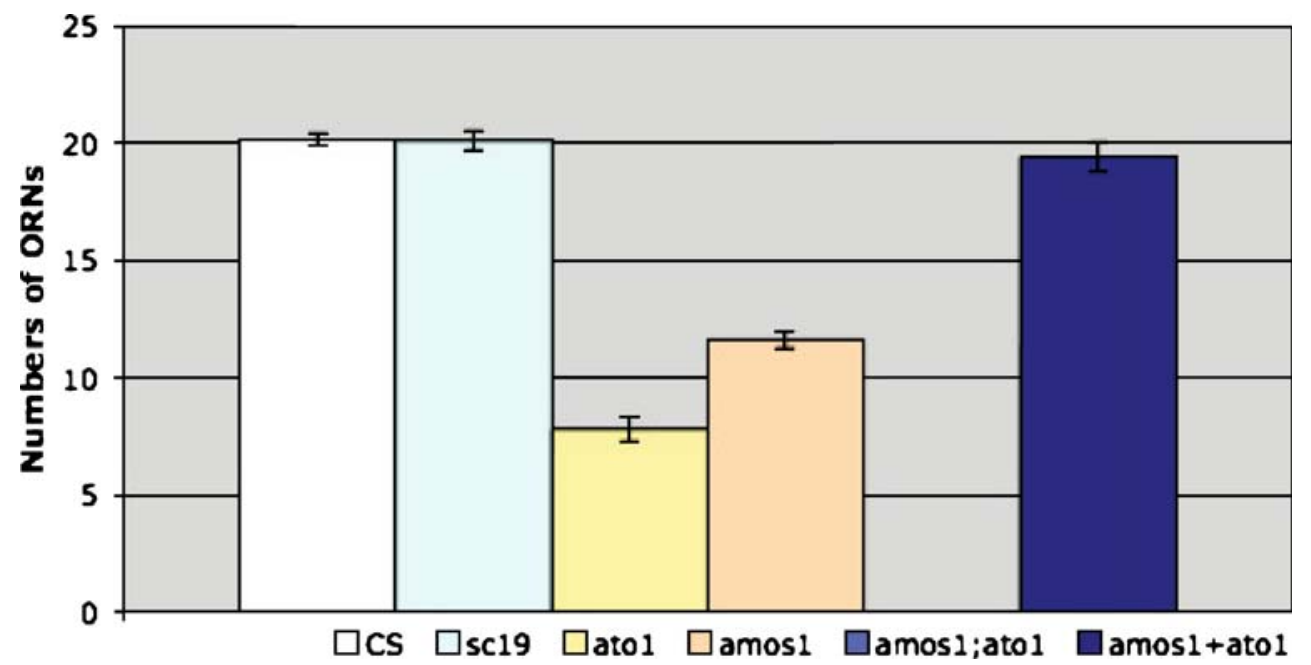

complete loss of ORNs in $\operatorname{amos}^{1}$; ato ${ }^{1}$ is also reflected by the disappearance of the dome (cf. Fig. 6e,f). However, the non-olfactory sensilla that surround the dome as well as the entire terminal organ seemed unaffected in the double mutant (cf. Fig. 6e,f, and f inset).

\section{Discussion}

Here, we studied two crucial developmental aspects of the DO, the unique olfactory organ of the larva. First, we determined its cellular composition, which allowed us to deduce the numbers of SOPs giving rise to the DO. Second, we analyzed the role of proneural genes in the formation of the DO, and in particular, its olfactory division.

The dorsal organ appears to be composed of 14 fused sensilla

Our immunocytochemical, in situ hybridization, and driver line expression data revealed the presence of almost equal numbers of accessory cells in the DO, i.e., of 14 sheath cells, 14 shaft cells, and 13 socket cells. There is ample evidence that the various types of insect external sensilla (except adult olfactory sensilla) develop via a stereotyped but individually modified cell-lineage, which can be traced back to a simple ancestral lineage (Fichelson and Gho 2003; Lai and Orgogozo 2004). Although the numbers and modality of the neurons vary in different sensillar types, every sensillum derives from a single SOP and comprises a single sheath, shaft, and socket cell. Hence, the numbers of accessory cells allow one to deduce the total number of SOPs in a complex sense organ. Consequently, we suggest that the DO derives from 14 SOPs and thus represents a compound of 14 sensilla (Table 1): six non-dome sensilla of the DO, a single sensillum associated with the terminal organ, and seven sensilla that may jointly form the dome. This interpretation is supported by the allocation of the 21 ORN dendrites to seven triplets. Why we only counted 13 socket cells instead of an expected 14 may be explained by the distal position of their cell bodies in the DO ganglion. We suggest that the 'missing' 14th socket cell belongs to the sensillum associated with the terminal organ. Its cell body might have escaped counting due to distal migration toward the terminal organ.

ato, amos, and $A S-C$ are the only proneural gene members controlling dorsal organ formation

Further support for the proposed composition of the DO comes from the effects of proneural mutants on neuron numbers (Fig. 2). Loss-of-function mutants of all known proneural genes that affect adult sensilla, i.e., ato, amos, and the $A S-C$ genes, reduced the numbers of neurons in the DO, suggesting that all of them are implicated in DO formation. When comparing the numbers of missing neurons in mutant pairs with the number of missing neurons in double mutants, no significant difference was observed for ${s c^{19}}^{19}$ amos $^{1}$ and ato ${ }^{1}$-amos ${ }^{1}$ combinations, indicating that amos acts independently in SOP specification. In contrast, the loss of additional three neurons in the $s c^{19}$; ato ${ }^{1}$ double mutant compared to the single mutants may suggest redundant functions of $A S-C$ and ato in the specification of subsets of DO neurons. An element of redundancy between $A S-C$ and ato has been reported for the formation of the $\mathrm{P}$ cell chordotonal precursor (Jarman et al. 1995). Triple mutants $s c^{B 57}$; amos $^{l}$; ato ${ }^{l}$ involving a deletion of the entire $A S-C$ locus showed a complete loss of neurons in the DO, whereas the single mutants $s c^{19}$, 
Fig. 6 Fine structural (a-d; third larval instar) and light microscopic effects (e, f; second instar) of proneural mutants on the DO. In the wild type, a cross-section below the dome shows the typical arrangement of the 21 ORN dendrites as seven triplets (a). The $12 \mathrm{ORN}$ dendrites present in amos $^{1}$ (b) are clustered as four triplets, whereas in ato $^{I}$ (c), 8 ORN dendrites were found to be grouped as two triplets and one pair. Also, ato ${ }^{l}$ displays some variability in dendritic fine structure (d). The dome, shown in the wild type (e, arrow), is lost in the double mutant (f, arrow). In contrast, the multisensillar terminal organ $(\mathbf{e}, \mathbf{f}, T O)$ as well as the nonolfactory sensilla of the DO, which are located on the cuticular rim surrounding the dome (e, small arrows), persist in amos $^{l} ;$ ato $^{l}$ (f, inset). Scale bars: $0.1 \mu \mathrm{m}(\mathbf{a}-\mathbf{d}) ; 10 \mu \mathrm{m}(\mathbf{e}, \mathbf{f})$
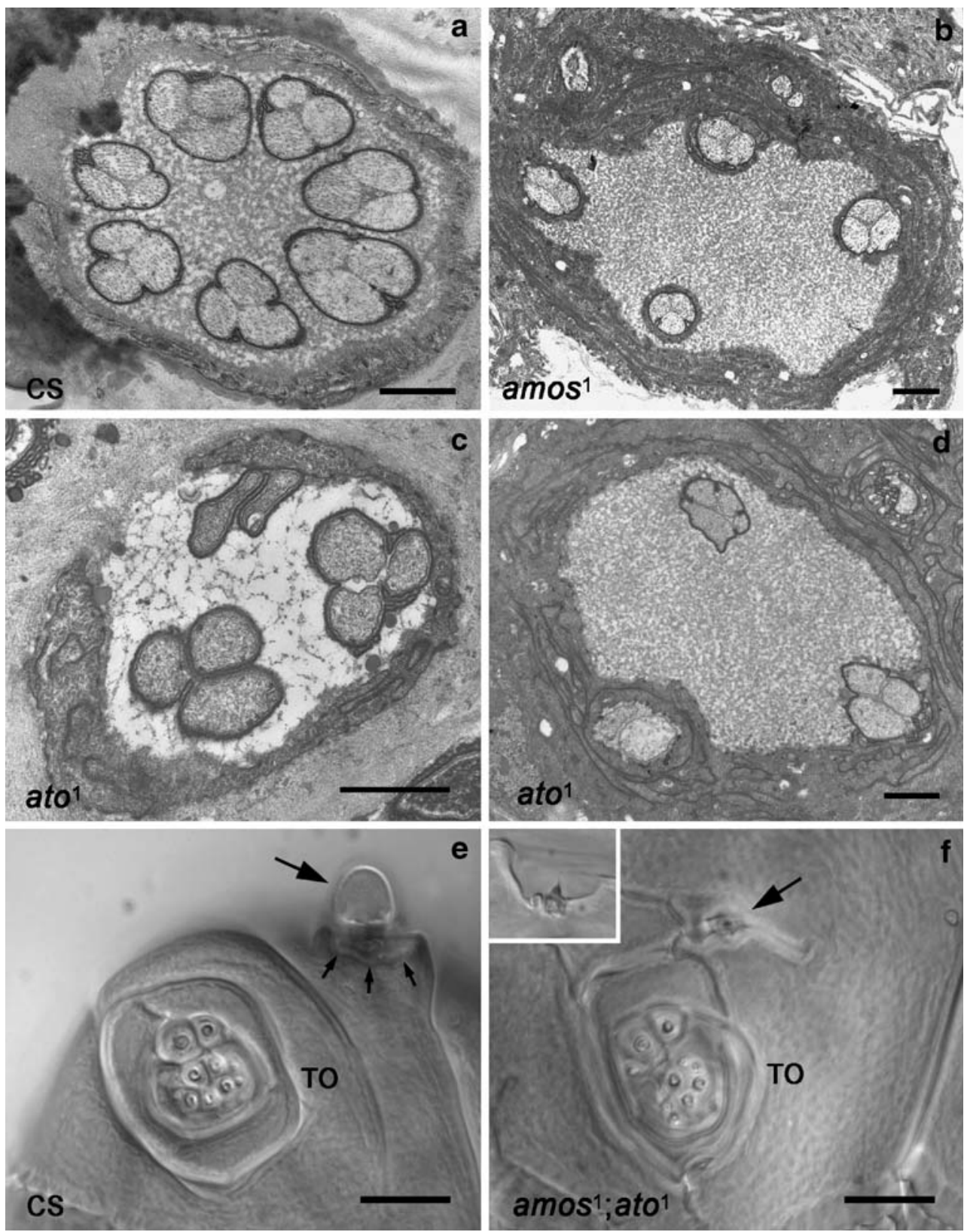

Table 1 Deduced sensillar and cellular composition of the dorsal organ

\begin{tabular}{lrrrr}
\hline & $\begin{array}{l}\text { Olfactory } \\
\text { sensilla } \\
\text { (dome) }\end{array}$ & $\begin{array}{l}\text { Non- } \\
\text { olfactory } \\
\text { sensilla }\end{array}$ & $\begin{array}{l}\text { DO sensillum } \\
\text { innervating } \\
\text { terminal organ }\end{array}$ & Total \\
\hline SOPs & 7 & 6 & 1 & 14 \\
Neurons & 21 & 12 & 3 & 36 \\
Sheath cells & 7 & 6 & 1 & 14 \\
Shaft cells & 7 & 6 & 1 & 14 \\
Socket cells & 7 & 6 & $1 ?$ & $14 ?$ \\
\hline
\end{tabular}

Question marks refer to the 'missing' socket cell (see text), which is supposedly associated with the atypical DO sensillum innervating the terminal organ. $a^{a m o s}{ }^{l}$, and $a t o^{l}$ together still had eight neurons. Because $s c^{19}$; amos $^{l}$; ato ${ }^{l}$ mutant escapers were not recovered, it remains unknown whether the corresponding proneural genes have partially redundant functions in specifying other DO neurons (see below) or whether the asense gene (González et al. 1989), which is deleted in $s c^{B 57}$, is involved. However, we were not able to detect any significant differences in DO neuron numbers between $s c^{19}$ and $s c^{B 57}$ mutant embryos. Moreover, asense is known to be required for the correct differentiation of sensory organs rather than providing a proneural role (Bertrand et al. 2002). In any case, ato, amos, and the $A S-C$ genes appear to be the only proneural genes controlling DO formation. 
ato and amos, but not $A S$ - $C$, control olfactory receptor neuron specification in the dorsal organ

The total loss of ORNs in ato ${ }^{1}$ amos $^{1}$ and the persistence of all 21 ORNs in $s c^{19}$ demonstrate that ato and amos, but not $A S-C$, are implicated in larval ORN specification (Fig. 5). Hence, similar to adult olfactory sensilla (Gupta and Rodrigues 1997; Goulding et al. 2000), ato and amos appear to be the only proneural genes controlling ORN formation in the DO. Thus, the genetic processes regulating embryonic and postembryonic olfactory development are conserved, regardless of striking anatomical and developmental differences, i.e., recruitment versus cell lineage (see below). The loss of about 12 ORNs in ato ${ }^{1}$ and 8 ORNs in amos $^{1}$ corresponds to the number of lost neurons in the double mutant, suggesting that these two genes are controlling complementary olfactory sensilla of the dome. This is compatible with our interpretation that amos acts independently of the other two proneural genes (see above). Interestingly, although ato and amos appear to play independent proneural functions for separate subsets of the olfactory SOPs, our expression data suggest that they might be coexpressed in some of these SOPs. In this case, ato expression depends on amos function. For these cells, we suggest that amos provides the proneural function to specify the SOPs and also activates ato, which may play some other downstream function. Compatible with such an additional function of ato in an amos-dependent SOP is our observation of a pair of ORN dendrites (apart from two triplets) in $a t o^{1}$, a phenotype that may be caused by modified patterns of cell division or cell death.

Given that ato and amos are controlling different types of adult olfactory sensilla (Gupta and Rodrigues 1997; Goulding et al. 2000; Jhaveri et al. 2000; zur Lage et al. 2003), the distinct roles of these two genes in different types of dome SOPs raise the question whether the dome is composed of two distinct sensillar types. In this context, it would be interesting to study which of the known larval ORs (Fishilevich et al. 2005; Kreher et al. 2005) are expressed in the ORNs controlled by ato and those controlled by amos. Yet, because $\mathrm{Or}$ genes are expressed late during differentiation, at least in adult ORNs (Clyne et al. 1999), simultaneous expression of proneural and $\mathrm{Or}$ genes is unlikely.

Model of proneural specification of the dorsal organ

Based on our data, the role of the three proneural genes in DO formation can be interpreted as follows (Table 2, Fig. 7):

(1) amos is the exclusive proneural gene specifying three of the seven olfactory sensilla; it acts independently of ato and $A S-C$. (2) ato is the exclusive proneural gene for the remaining four olfactory sensilla; moreover, together with
Table 2 Effects of proneural mutants on the deduced numbers of SOPs and neurons in the dorsal organ

\begin{tabular}{lcc}
\hline & Lost SOPs & Lost neurons \\
\hline Wild type & 0 & 0 \\
sc $^{19}$ & $2 ?$ & 7 \\
amos $^{1}$ & 3 & 9 \\
ato $^{1}$ & 4 & 12 \\
amos $^{1} ;$ ato $^{1}$ & 7 & 21 \\
amos $^{1}+$ ato $^{1}$ & 7 & 21 \\
sc $^{19} ;$ amos $^{1}$ & $5 ?$ & 16 \\
sc $^{19}+$ amos $^{1}$ & $5 ?$ & 16 \\
sc $^{19} ;$ ato $^{1}$ & $7 ?$ & 22 \\
sc $^{19}+$ ato $^{1}$ & $6 ?$ & 19 \\
sc $^{B 57} ;$ amos $^{1} ;$ ato $^{1}$ & 14 & 36 \\
sc $^{19}+$ amos $^{1}+$ ato $^{1}$ & $9 ?$ & 28
\end{tabular}

SOP numbers shown with a question mark are deduced from the numbers of lost neurons.

$A S-C$, it controls specification of one non-olfactory sensillum, comprising the three extra neurons that are lost in $s c^{19}$; ato $^{1}$. (3) $A S-C$ controls the six remaining non-olfactory sensilla of the DO (apart from the interaction with ato for the seventh non-olfactory sensillum). As discussed above, one explanation of the different neuron numbers in $s c^{B 57}$; amos $^{1}$; ato ${ }^{1}$ triple mutants compared to the three single mutants $s c^{19}$, amos ${ }^{1}$, and $a o^{1}$ is based on redundant functions between proneural gene members in the specification of particular non-olfactory sensilla. In such a model, four of these sensilla would be controlled by triple ato, amos, and $A S-C$ function, two by $A S-C$ alone, and the remaining one by combined ato/AS-C function (see above;

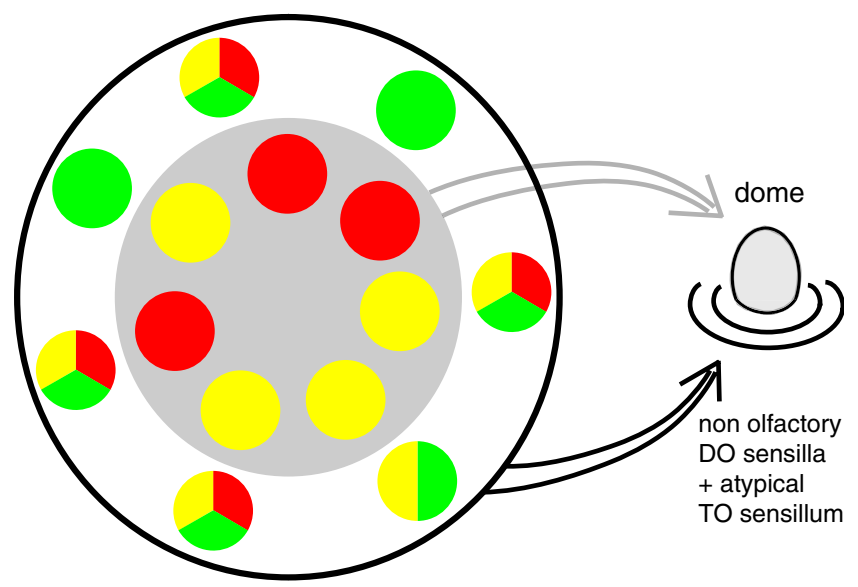

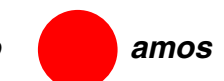

amos

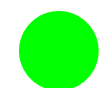

AS-C

Fig. 7 Possible role of ato (yellow), amos (red), and AS-C (green) in specifying the 14 putative SOPs of the DO. SOPs giving rise to the olfactory dome sensilla are shown in the gray center part, those of the non-olfactory sensilla in the periphery. The model is based on genetic redundancy in five of the non-olfactory SOPs 
Fig. 7). Interestingly, in the first-born chordotonal SOPs, Ato and $\mathrm{Sc}$ are coexpressed, and the SOP is often formed in ato mutants but not in $A S-C$; ato double mutants (Jarman et al. 1995). Yet, suppose that the redundancy interpretation is correct, it remains unclear why the neurons of this last sensillum do not become extra ORNs in $s c^{19}$. As an alternative explanation to redundancy, repression between proneural gene members seems possible, either within a given SOP or between neighboring SOPs. Our expression pattern analysis, however, reveals no sign of de-repression in mutants.

The model proposed above is based on the assumption that the sensilla giving rise to the DO develop via a strict cell lineage, each initiated by a distinct SOP. Alternatively, DO formation may involve recruitment of cells by a founder cell, similar to the development of the compound eye (reviewed by Freeman 1997), the pentascolopidial organ Ich5 (zur Lage et al. 1997; Okabe and Okano 1997), and adult olfactory sensilla (Ray and Rodrigues 1995; Reddy et al. 1997). However, we believe this alternative to be less likely for two reasons. First, our cell counts allow a straightforward lineage-based interpretation. Moreover, in contrast to eye or antennal development, DO formation is not embedded in a 'sensory field' that comprises hundreds of similar, closelyspaced elements, such as ommatidia or antennal sensilla. Rather, the DO is a unique, complex organ, which in Musca includes at least six morphologically distinct types of sensilla (Chu and Axtell 1971; Chu-Wang and Axtell 1972). The formation of such an intricate organ would be hard to explain based on cell recruitment. This interpretation does, however, not exclude cross talk between the different DO sensilla during development.

Overall, our data show that the genetic processes controlling larval and adult chemosensory organ specification are conserved, in spite of their different anatomy and regardless of likely discrepancies in the developmental mechanisms involved. A number of interesting issues remain to be elucidated in DO formation, such as the exact celllineages of the 14 sensilla, the detachment of the DO sensillum projecting toward the terminal organ, or the fusion of the seven olfactory sensilla to form a common dome.

Acknowledgments We are very grateful to F. Python (Fribourg) for providing Fig. 1a and to W. Boll (Zürich) and J. Colomb (Fribourg) for helpful comments. This work was supported by the Swiss National Funds (grants no. 31-63447.00, 3100A0-105517).

\section{References}

Abramoff MD, Magelhaes PJ, Ram SJ (2004) Image processing with ImageJ. Biophoton Int 11:36-42

Behan M, Ryan MF (1978) Ultrastructure of antennal sensory receptors of Tribolium larvae (Coleoptera: Tenebrionidae). Int J Insect Morphol Embryol 7:221-236
Bertrand N, Castro DS, Guillemot F (2002) Proneural genes and the specification of neural cell types. Nat Rev Neurosci 3:517-530

Cabrera CV (1992) The generation of cell diversity during early neurogenesis in Drosophila. Development 115:893-901

Campuzano S, Modolell J (1992) Patterning of the Drosophila nervous system: the achaete-scute gene complex. Trends Genet 8:202-208

Chu IW, Axtell RC (1971) Fine structure of the dorsal organ of the house fly larva, Musca domestica L. Z Zellforsch Mikrosk Anat 117:17-34

Chu-Wang IW, Axtell RC (1972) Fine structure of the terminal organ of the house fly larva, Musca domestica L. Z Zellforsch Mikrosk Anat 127:287-305

Clyne PJ, Warr CG, Freeman MR, Lessing D, Kim J, Carlson JR (1999) A novel family of divergent seven-transmembrane proteins: candidate odorant receptors in Drosophila. Neuron 22:327-338

Doe CQ, Chu-LaGraff Q, Wright DM, Scott MP (1991) The prospero gene specifies cell fates in the Drosophila central nervous system. Cell 65:451-464

Fichelson P, Gho M (2003) The glial cell undergoes apoptosis in the microchaete lineage of Drosophila. Development 130:123-133

Fishilevich E, Domingos AI, Asahina K, Naef F, Vosshall LB, Louis M (2005) Chemotaxis behavior mediated by single larval olfactory neurons in Drosophila. Curr Biol 15:2086-2096

Freeman M (1997) Cell determination strategies in the Drosophila eye. Development 124:261-270

Garcia-Bellido A (1979) Genetic analysis of the achaete-scute system of Drosophila melanogaster. Genetics 91:491-520

Gendre N, Lüer K, Friche S, Grillenzoni N, Ramaekers A, Technau GM, Stocker RF (2004) Integration of complex larval chemosensory organs into the adult nervous system of Drosophila. Development 131:83-92

Gho M, Lecourtois M, Geraud G, Posakony JW, Schweisguth F (1996) Subcellular localization of Suppressor of Hairless in Drosophila sense organ cells during Notch signalling. Development 122:16731682

Ghysen A, Dambly-Chaudière C, Jan LY, Jan YN (1993) Cell interactions and gene interactions in peripheral neurogenesis. Genes Dev 7:723-733

González F, Romani S, Cubas P, Modolell J, Campuzano S (1989) Molecular analysis of the asense gene, a member of the achaetescute complex of Drosophila melanogaster, and its novel role in optic lobe development. EMBO J 8:3553-3562

Goulding SE, zur Lage PI, Jarman AP (2000) amos, a proneural gene for Drosophila olfactory sense organs that is regulated by lozenge. Neuron 25:69-78

Gupta BP, Rodrigues V (1997) atonal is a proneural gene for a subset of olfactory sense organs in Drosophila. Genes Cells 2:225-233

Hartenstein V, Posakony JW (1989) Development of adult sensilla on the wing and notum of Drosophila melanogaster. Development 107:389-405

Hassan BA, Bermingham NA, He Y, Sun Y, Jan YN, Zoghbi HY, Bellen $\mathrm{HJ}$ (2000) atonal regulates neurite arborization but does not act as a proneural gene in the Drosophila brain. Neuron 25:549-561

Holohan EE, zur Lage PI, Jarman AP (2006) Multiple enhancers contribute to spatial but not temporal complexity in the expression of the proneural gene, amos. BMC Devel Biol 6:53

Huang ML, Hsu CH, Chien CT (2000) The proneural gene amos promotes multiple dendritic neuron formation in the Drosophila peripheral nervous system. Neuron 25:57-67

Jan YN, Jan LY (1994) Neuronal cell fate specification in Drosophila. Curr Opin Neurobiol 4:8-13

Jarman AP, Grau Y, Jan LY, Jan YN (1993) atonal is a proneural gene that directs chordotonal organ formation in the Drosophila peripheral nervous system. Cell 73:1307-1321 
Jarman AP, Grell EH, Ackerman L, Jan LY, Jan YN (1994) atonal is the proneural gene for Drosophila photoreceptors. Nature 369:398-400

Jarman AP, Sun Y, Jan LY, Jan YN (1995) Role of the proneural gene atonal in formation of Drosophila chordotonal organs and photoreceptors. Development 121:2019-2030

Jhaveri D, Sen A, Reddy GV, Rodrigues V (2000) Sense organ identity in the Drosophila antenna is specified by the expression of the proneural gene atonal. Mech Dev 99:101-111

Kankel DR, Ferrus A, Garen SH, Harte PJ, Lewis PE (1980) The structure and development of the nervous system. In: Ashburner M, Wright TRF (eds) The genetics and biology of Drosophila, vol. 2d. Academic, New York, pp 295-368

Kavaler J, Fu W, Duan H, Noll M, Posakony JW (1999) An essential role for the Drosophila Pax2 homolog in the differentiation of adult sensory organs. Development 126:2261-2272

Kreher SA, Kwon AY, Carlson JR (2005) The molecular basis of odor coding in the Drosophila larva. Neuron 46:445-456

Lai EC, Orgogozo V (2004) A hidden program in Drosophila peripheral neurogenesis revealed: fundamental principles underlying sensory organ diversity. Dev Biol 269:1-17

Larsson MC, Domingos AI, Jones WD, Chiappe ME, Amrein H, Vosshall LB (2004) Or83b encodes a broadly expressed odorant receptor essential for Drosophila olfaction. Neuron 43:703-714

Okabe M, Okano H (1997) Two-step induction of chordotonal organ precursors in Drosophila embryogenesis. Development 124:1045-1053

Patel NH (1994) Imaging neuronal subsets and other cell types in whole-mount Drosophila embryos and larvae using antibody probes. In: Goldstein LSB, Fyrberg EA (eds) Practical uses in cell and molecular biology. Academic, San Diego, pp 446-485

Python F, Stocker RF (2002) Adult-like complexity of the larval antennal lobe of $D$. melanogaster despite markedly low numbers of odorant receptor neurons. J Comp Neurol 445:374-387

Ray K, Rodrigues V (1994) The function of the proneural genes achaete and scute in the spatio-temporal patterning of the adult labellar bristles of Drosophila melanogster. Roux's Arch Dev Biol 203:340-350
Ray K, Rodrigues V (1995) Cellular events during development of the olfactory sense organs in Drosophila melanogaster. Dev Biol $167: 426-438$

Reddy GV, Gupta B, Ray K, Rodrigues V (1997) Development of the Drosophila olfactory sense organs utilizes cell-cell interactions as well as lineage. Development 124:703-712

Romani S, Campuzano S, Macagno ER, Modolell J (1989) Expression of achaete and scute genes in Drosophila imaginal discs and their function in sensory organ development. Genes Dev 3:997-1007

Simpson P (1990) Notch and the choice of cell fate in Drosophila neuroepithelium. Trends Genet 6:343-345

Singh RN, Singh K (1984) Fine structure of the sensory organs of Drosophila melanogaster Meigen Larva (Diptera: Drosophilidae). Int J Insect Morphol Embryol 13:255-273

Stocker RF (2001) Drosophila as a focus in olfactory research: mapping of olfactory sensilla by fine structure, odor specificity, odorant receptor expression and central connectivity. Microsc Res Tech 55:284-296

Tautz D, Pfeifle C (1989) A non-radioactive in situ hybridization method for the localization of specific RNAs in Drosophila embryos reveals translational control of the segmentation gene hunchback. Chromosoma 98:81-85

Vaessin H, Grell E, Wolff E, Bier E, Jan LY, Jan YN (1991) prospero is expressed in neuronal precursors and encodes a nuclear protein that is involved in the control of axonal outgrowth in Drosophila. Cell 67:941-953

Villares R, Cabrera CV (1987) The achaete-scute gene complex of D. melanogaster: conserved domains in a subset of genes required for neurogenesis and their homology to myc. Cell 50:415-424

Vosshall LB, Amrein H, Morozov PS, Rzhetsky A, Axel R (1999) A spatial map of olfactory receptor expression in the Drosophila antenna. Cell 96:725-736

zur Lage PI, Jan YN, Jarman AP (1997) Requirement for EGF receptor signalling in neural recruitment during formation of Drosophila chordotonal sense organ clusters. Curr Biol 7:166-175

zur Lage PI, Prentice DR, Holohan EE, Jarman AP (2003) The Drosophila proneural gene amos promotes olfactory sensillum formation and suppresses bristle formation. Development 130:4683-4693 